East African Medical Journal Vol. 80. No. 8 August 2003

NORMAL AXIAL ANGLES OF THE KNEE JOINT IN ADULT INDIGENOUS MALAWIANS

P.S. Igbigbi, MBBS, MSc, B.C. Msamati, MD, PhD and B. Matanje, (Medical student) Department of Anatomy, College of Medicine, University of Malawi, Private

Bag 360, Chichiri, Blantyre 3, Malawi

Request for reprints to: Prof. P.S. Igbigbi, Department of Anatomy, College of Medicine, University of Malawi, Private Bag 360, Chichiri, Blantyre 3, Malawi

\title{
NORMAL AXIAL ANGLES OF THE KNEE JOINT IN ADULT INDIGENOUS MALAWIANS
}

\author{
P.S. IGBIGBI, B.C. MSAMATI and B. MATANJE
}

\begin{abstract}
Objective: To determine the normal axial angles of the knee joint in adult indigenous Malawians.

Design: A retrospective study.

Setting: Radiographs were collected from the archives of the $\mathrm{X}$-ray Department on subjects investigated from Queen Elizabeth Central Hospital in Blantyre City.

Subjects: X-ray films of 271 adult black subjects aged 18-67 years were studied.

Main outcome measures: Normal axial angles of the knee joint using standard methods were determined and compared with those reported for Caucasians previously studied.

Results: The mean femoral and mechanical angles of the femur and the knee joint were greater in Malawian subjects than in Caucasians previously reported, but the tibial angle of Malawians was less than those of Caucasians. The angle between the mechanical and anatomical axes of the femur was $3^{\circ}$ in Malawians, but $6^{\circ}$ in Caucasians. Malawians, had wider range of the mechanical angle of the Knee joint than Caucasians. These angles did not show significant sex differences in Malawians ( $P>0.1 ; 0.5$, respectively) but significant differences were observed in these angles between Malawians and Caucasians $(\mathbf{P}>0.001)$.

Conclusion: Our study has demonstrated comparative variations in means and ranges of normal axial angles between Malawians and Caucasians previously reported. Thus as a prerequisite for proper orthopaedic clinical practice in this part of the world, there is need for reference values of these angles.
\end{abstract}

\section{INTRODUCTION}

The knee joint is the largest and one of the most complex joints of the body. It is a weight-bearing joint, which allows free movement mostly in one plane and plays an important role in locomotion by shortening and lengthening of the lower limb (1). The weight of the body is supported on the vertically apposed ends of the two largest bones of the body, the femur and tibia. These together with ligaments, a strong capsule, and the reinforcing effects of aponeuroses and tendons, provide considerable stability for the joint especially during extension (1).

The configuration of the femoral neck is such that it overhangs the shaft and the anatomical axes of the femur and tibia do not coincide; these together result in the formation of the tibiofemoral angle. However, the joint centres of the hip, knee and ankle all lie on a straight line, forming the mechanical axis of the lower limb (Figure 1). This axis coincides with the anatomical axis of the tibia in the leg, while in the thigh it forms an angle of $6^{\circ}$ with the anatomical axis of the femoral shaft in Caucasians (1). The mechanical angle of the femur is therefore the femoral angle (FA), plus $6^{\circ}$ while the mechanical angle of the tibia is the same as the tibia angle (TA). The mechanical angle of the knee joint is the sum of the mechanical angles of femur
(MA) and tibia (TA, Figure 1). If the femoral neck shaft angle and the three joints of the lower limb are intact the mechanical axes of the femur and tibia correspond to the mechanical axis of the lower limb (1).

Deviations in the axes of the knee can be physiological or pathological. In the former, the lower leg is bowed in a varus direction at birth until after a child begins to walk and the knee axis deviated to a slight valgus. This, however, goes back to normal before the age of ten years. Pathological variations of the axes are rare and they occur in congenital deformations, after trauma or infection, or as a result of metabolic diseases. A deviation of $15^{\circ}$ from the normal axis is usually an indication for operative treatment (2).

Previous studies in Caucasians (1,3-7) have provided values for the femoral, tibia and mechanical angles of the knee joint. They have also shown the importance of the axes in the radiographic assessment of total knee arthroplasty, tibial torsion defects as well as the proper alignment or otherwise of the femur and tibia . Furthemore, Milner (8) confirmed that the accurate measurement of the alignment of the tibia (indicated by the tibial angle) is important in both clinically and in research especially since it provides a more accurate method of measurement of angulation after fractures of the tibia. Despite the clinical importance of the mechanical angle of the knee 
joint, literature on it is not available on Africans. Indeed, a medline search revealead no study on African subjects. This article is therefore an attempt to provide baseline values for femoral, tibial and mechanical angles of the knee joints of adult Malawians.

\section{MATERIALS AND METHODS}

We investigated 271 unilateral antero-posterior radiographs of the knee joint comprising 149 males and 122 females indigenous Malawian subjects aged 18 to 67 years from the archives of Queen Elizabeth central hospital in Blantyre city. The X-rays had been taken during the investigation of some musculoskeletal problem in the limb, and we selected those that proved normal. Only radiographs in which the extremity was positioned with the patella straight ahead were used. If, however, there was torsion or bowing of the tibia, a longitudinal axis was estimated between the patella and the mid-point of the ankle joint.

Each radiograph was placed on an X-ray viewer for measurement of the femoral (FA), tibial (TA) and mechanial angles of the femur (MA), (Figure 1). Each of the authors assessed the radiographs individually using a goniometer and a ruler, each angle being measured twice to ensure accuracy. The observers agreed on the precise definition of the landmarks to be used and these involved drawing two longitudinal axis, one through the centre of the femoral shaft (AB), and one through the centre of the tibial shaft $(\mathrm{CD})$. The femoral axis joined the midpoint of the widest part of the lower end of femur and the centre of the shaft $10 \mathrm{~cm}$ above, while the tibial axis joined the midpoint of the widest upper end and the centre of the tibial shaft $10 \mathrm{~cm}$ below this landmark. Two other lines drawn at tangents to the lateral and medial extremities of the femoral condyles (EF) and the tibial plateau (GH), (Figure 1). The mechanical angle of the knee joint is the sum of TA and MA while MA minus FA, represents angle between the mechanical and anatomical axes of the femoral shaft. No significant difference was found between the means of the right and left sides $(\mathrm{P}>0.1)$ and hence the data were pooled. The observers used similar landmarks in their measurement, and the lines for the angles were erased before the next observer used the film. Inter-observer error was tested and the variation among the observers averaged less than $1^{\circ}$. The anatomical landmarks we used the standard method of Keats $e t$ al. (3), were also used in the previous studies on Caucasians with which our data were compared.

Statistical analysis: The name, age and sex of each subject on the X-ray jacket together with the angles measured were recorded. The results were then anlysed using SPLUS statistical package for Windows version 4 and were compared with previous reports on adult Caucasians, aged 20-76 years. The results were presented as means \pm standard deviations and the analysis was by two sample t-test with Welch's correction because of the multiple comparisons performed on the data.

\section{RESULTS}

Table 1 compares the femoral and the axial angles of the knee in adult Malawian and Caucasian subjects. In both sexes the average femoral angle was greater in Malawians than in Caucasians, but the average tibial angle was greater in Caucasians than in Malawians. On the other hand the mechanical angles of the femur and knee joint were grater in Malawians than in Caucasians. These differences were greater with the mechanical angle of the femur than with the mechanical angle of the knee joint; the difference in range of $30^{\circ}$ for the femoral angle was greater than the $10^{\circ}$ reported on Caucasians (Table 1). The mean angle between the mechanical and anatomical axes of the femur was $3^{\circ}$ for Malawians while $6^{\circ}$ was reported for Causasians (1). However, Malawians had a wider range for the mechanical angle of the knee joint $\left(166-194^{\circ}\right)$ than Caucasians $\left(172-187^{\circ}\right)$.

Table 1

Comparisons of the axial angles of the knee joint in adult Negroid Malawians with data on Caucasians found in the listed literature

\begin{tabular}{|c|c|c|c|c|c|}
\hline \multirow[b]{2}{*}{ Angle } & \multicolumn{2}{|c|}{ Malawians } & \multicolumn{2}{|c|}{ Caucasians } & \multirow[b]{2}{*}{ Authors (s) } \\
\hline & $\begin{array}{l}\text { Males } \\
(n=149)\end{array}$ & $\begin{array}{l}\text { Females } \\
(\mathrm{n}=122)\end{array}$ & $\begin{array}{l}\text { Males } \\
(\mathrm{n}=25)\end{array}$ & $\begin{array}{l}\text { Females } \\
(n=25)\end{array}$ & \\
\hline \multicolumn{6}{|l|}{ Femoral angle (FA) } \\
\hline Range & $72-102^{\circ}$ & $80-102^{\circ}$ & $75-85^{\circ}$ & $75-85^{\circ}$ & Keats et al. \\
\hline Mean and SD & $89.4-5.6^{\circ}$ & $90-5.2^{\circ}$ & $80.2-2.0^{\circ}$ & $81.2-2.0^{\circ}$ & 1966(3) Nigel \\
\hline Average: male and female & $90^{\circ}$ & & $90^{\circ}$ & & et al., 1988(1) \\
\hline \multicolumn{6}{|l|}{ Tibial angle (TA) } \\
\hline Range & $80-94^{\circ}$ & $83-96^{\circ}$ & $85-100^{\circ}$ & $87-98^{\circ}$ & Keats et al. \\
\hline Mean and SD & $89.6 \pm 2.9^{\circ}$ & $89.1 \pm 3.2^{\circ}$ & $93.5 \pm 3.5^{\circ}$ & $92.4-2.5^{\circ}$ & 1966(3) Nigel \\
\hline Average: male and female & & $93^{\circ}$ & $87^{\circ}$ & & et al. 1998(1) \\
\hline \multicolumn{6}{|c|}{ Mechanical angle (MA) of femur } \\
\hline Range & $85-100^{\circ}$ & $87-98^{\circ}$ & NA & NA & Keats et al \\
\hline Mean and SD & $92.6 \pm 6.8^{\circ}$ & $93.3^{\circ} \pm 4.6^{\circ}$ & NA & NA & 1966(3) Nigel \\
\hline Average; male and female & & $93^{\circ}$ & & $93^{\circ}$ & et al. 1998(1) \\
\hline \multicolumn{6}{|c|}{ Mechanical angle of the knee joint (TA + MA) } \\
\hline Range & $165-194^{\circ}$ & $170-194^{\circ}$ & $172-187^{\circ}$ & $174-185^{\circ}$ & Keats et al \\
\hline Mean and SD & $182.2 \pm 4.9^{\circ}$ & $182.5 \pm 3.9^{\circ}$ & $180 \pm 3.5^{\circ}$ & $180 \pm 2.5^{\circ}$ & 1966(3) Nigel \\
\hline Average; male and female & & $182^{\circ}$ & & $180^{\circ}$ & et al. $1998(1)$ \\
\hline \multicolumn{6}{|c|}{$\begin{array}{l}\text { The mean angle between the anatomical and mechanical axes of femur } \\
\text { (MA-FA) }\end{array}$} \\
\hline $93-90^{\circ}$ & & $3^{\circ}$ & $6^{\circ}$ & & $\begin{array}{l}\text { 1966(3) Nigel } \\
\text { et al. } 1998(1)\end{array}$ \\
\hline
\end{tabular}


Table 2

A comparison of the femoral, tibial and mechanical angles of the femur and knee joint in adult Malawian and Caucasian subjects

\begin{tabular}{|c|c|c|c|}
\hline Contrast between men and women & T-values & $\mathrm{P}$ & Significance \\
\hline In femoral angles (Malawians) & 1.60 & $>0.1$ & ns \\
\hline In tibial angles (Malawians) & 1.25 & $>0.1$ & ns \\
\hline In mechanical angles of femur (Malawians) & 1.05 & $>0.1$ & ns \\
\hline In mechanical angles of the knee joint (Malawians) & 0.49 & $>0.5$ & ns \\
\hline In femoral angles (Malawians and Caucasian men) & 13.51 & $>0.001$ & $\mathrm{~s}$ \\
\hline In femoral angles (Malawians and Caucasian women) & 15.28 & $>0.001$ & $\mathrm{~s}$ \\
\hline In tibial angles (Malawians and Caucasian men) & 4.61 & $>0.001$ & $\mathrm{~s}$ \\
\hline In tibial angles (Malawians and Caucasian women) & 6.71 & $>0.001$ & $\mathrm{~s}$ \\
\hline In mechanical angles of femur (Malawians and Caucasians both sexes) & 4.72 & $>0.001$ & $\mathrm{~s}$ \\
\hline In mechanical angles of knee joint(Malawians and Caucasian men) & 3.84 & $>0.001$ & $\mathrm{~s}$ \\
\hline In mechanical angles of knee joint(Malawians and Caucasian women) & 4.00 & $>0.001$ & $\mathrm{~s}$ \\
\hline
\end{tabular}

Note: $\mathrm{ns}=$ not significant, $\mathrm{s}=$ significant. Since the sample sizes are large, the normal approximation was used. These estimates were produced by SPLUS

\section{Figure 1}

A diagram to illustrate the axial angles of the knee joint

\section{DISCUSSION}

We have demonstrated probably for the first time that the mean mechanical angle of the knee joint in an African population was significantly different from the mean value reported for Caucasians $(\mathrm{P}<0.001)$. We have also shown that the range for Malawians was wider (165-194 $)$ or $29^{\circ}$ degrees difference while in Caucasians it was (172$187^{\circ}$ ) or $15^{\circ}$ difference. This strengthens the need to have a reference range of values for a given population. In this case, however, the angle also exhibits racial variations. Previous studies have shown that the femora of blacks are generally longer and have less anterior curvature than those of whites $(9,10)$.

Whites have more anterior bowing and shorter femurs than blacks could explain the racial difference we have reported here, especially since females with shorter femurs also have lower femoral and mechanical angles of the femur. This might also account for the variation in the mean angle between the mechanical and anatomical axes of the femur of $3^{\circ}$ for Malawians and $6^{\circ}$ for Caucasians (1). It must be pointed out that the mechanical angle of the femur is dependent on the femoral angle (FA) resulting in the mean angle, $3^{\circ}$ in our series but $6^{\circ}$ in Caucasians (1).

This study has also demonstrated probably for the first time in black Africans that the mechanical angle of the knee joint does not exhibit sexual dimorphism as was reported on Caucasians $(1,3)$. Our study has further demonstrated that the mean femoral angle (FA) in Malawians was significantly greater than the mean angle for Caucasians, whereas the mean tibial angle for Caucasians was significantly greater than the mean angle for Malawians $(\mathrm{P}<0.001)$. In Malawians, both the mean femoral and tibial angles were close in value of $90^{\circ}$ and $89^{\circ}$, as opposed to $81^{\circ}$ and $93^{\circ}$ for Caucasians, a factor that might explain in part the morphological variations observed between Malawian Africans and Caucasians. By extension the same argument would explain the variations in were observed between Malawians and Caucasians in all the angles $(\mathrm{P}<0.001$, Table 2$)$.
$\mathrm{AB}$, longitudinal axis through femur; $\mathrm{CD}$, longitudinal axis , the lateral an tangent to the medical extremities of the tibial plateau; FA, femoral angle;

Table 2, compared the femoral, tibial and mechanical angles of the femur and knee joint between the sexes in adult Malawians as well as in adult Caucasians previously reported. All four angles showed no significant sex differences (Table 2: P>0.1 for FA, TA and MA; and 
configuration of the femoral neck and the angulations of the femoral shaft as indeed was demonstrated previously between Nigerians and East Africans on one hand and on the other Caucasians (3,11-13). However, we have now demonstrated for the first time in black Africans that this variation translates to $3^{\circ}$ angulations of the femoral shaft in Malawians, in contrast to the reported $6^{\circ}$ in Caucasians (1).

In any study of this nature, certain limitations are bound to occur. The method, variability of measurements of the X-ray films due to magnification aberrations, interobserver variation errors can arise. In this study a previously tested method of Keats et al., (3) and the same anatomical landmarks were used in taking the measurements, as previously reported on Caucasians with whose data we compared to our own. The questions of variability due to inter-observer errors were tested and averaged less than $1^{\circ}$ as indicated above. It must be pointed out that all X-ray films were taken at the standard focal - film distance of 92 $\mathrm{cm}$ and objective-film distance of $5 \mathrm{~cm}$ and a $2.86 \%$ correction factor was applied to all measurements as in previous reports (3). We were therefore satisfied that these limitations were adequately addressed in our study.

In conclusion, our study has demonstrated comparative variations in means and ranges of the femoral, tibia and mechanical angles of the knee joint between our subjects and Caucasians. More importantly, we have shown a major variation in the angle formed by the anatomical and mechanical axes to be $3^{\circ}$ in our subjects in contrast to $6^{\circ}$ reported in Caucasians. This variation is a result of the of the difference in the angulation of the femoral shaft, which could partly explain the differences seen in body proportions between Africans and Caucasians. Moreover, we have indicated the clinical importance of establishing a reference range of normal values of the axial angles of the knee joint in a given population. Establishing such values would help the orthopaedic surgeon during radiographic assessment for total knee arthroplasty, in tibial torsion defects and in the proper alignment of the femur or tibia. Therefore, in addition to measurement of the angles of the opposite normal knee joint in adult Malawians, we recommend the establishment of normal ranges of axial angles as a prerequisite for proper orthopaedic clinical practice in this part of the world.

\section{REFERENCES}

1. Nigel P., Derek F. and Roger S. The hip joint . In: Anatomy and human movement - structure and function. Ed. 3, Oxford Butterwoth - Heinemann 1998; pp. 432-438.

2. Hefti F. Deviations in the axes of the lower extrenities. Orthopade. 2000; 29: 814-820.

3. Keats T.E., Teeslink R., Diamond A.E. and Williams J.H. Normal axial relationships of the major joints. Radiol. 1966; 87:904 - 907.

4. Lampert C., Thomann B. and Brunner R. Tibial torsion deformities. Orthopade. 2000; 29: 802-807.

5. Nagamine R., Miura H., Bravo C.V., Urabe K., Matsuda S., Miyanishi K., Hirata G. and Iwamoto Y. Anatomic variations should be considered in total knee arthroplasty. J. Orthop. Sci. 2000, 5:232-237.

6. Perrilo-Marcone A., Barret D.S. and Taylor M. Overall alignment in valgus results in lower migration rates and lower incidence of loosening. J. Anthroplasty . 2000; 15: 1020-1027.

7. Bach C.M., Steingruber I.E., Peer S., Nogler M., Wimmer C. and Ogon M. Radiographic assessment in total knee orthoplasty. Clin. Orthop. 2001; 385: 144-150.

8. Milner S.A. A more accurate method of measurement of angulation after fractures of the tibia. J. Bone Joint Surg. 1997; 79:972-974.

9. Trotter M. and Gleser G.C. Estimation of stature form long bones of American Whites and Negroes. Am. J. Phys. Anthrop. 1952; 10:463-514.

10. Steward T.D. Anterior femoral curvature: its utility for race identification. Hum. Biol. 1962; 34:49-62.

11. Singh S.P., Ekanem G.J., Ani O.E.O. and Onuba O. A study of the Collo-diaphyseal angle of the femur in Nigerians. West Afr. J. Anat. 1986; 1:28-32.

12. Igbigbi P.S. and Kwatampora J. Lower limb angles of Eastern African subjects. West Afr. J. Anat. 1986; 5: 9-15.

13. Igbigbi P.S. The Collo-diaphyseal angle of the femur in Eastern Africa subjects. Clinical Anatomy 2002. (In press). 